\title{
La punitividad del público como reacción instrumental y expresiva ante las amenazas al comienzo del siglo XXI. Evidencias del Área Metropolitana de Buenos Aires*
}

DOI: https://doi.org/10.18046/recs.i31.3720

\author{
Public Punitiveness as an Instrumental and Expressive \\ Reaction against Threats at the Beginning of the 21st Century. \\ Evidence of the Metropolitan Area of Buenos Aires
}

\section{María Alejandra Otamendi ${ }^{* *}$}

Universidad de Buenos Aires (Buenos Aires, Argentina)

\footnotetext{
* Este artículo se elaboró a partir de la tesis doctoral Demandas de "mano dura": punitividad pública de los residentes del Área Metropolitana de Buenos Aires (200o-2010), realizada en el año 2013 por la autora, en cotutela entre la Universidad de Buenos Aires (UBA) y la École des Hautes Études en Sciences Sociales (EHESS). Artículo de investigación recibido el 19.09.2019 y aceptado el 29.03.2020.

** Investigadora asistente del CONICET, Instituto de Investigaciones Gino Germani, Universidad de Buenos Aires (Argentina). Correo electrónico: otamendialejandra@gmail.com ORCID: https://orcid.org/oooo-ooo2-8271-7632
} 


\section{Cómo citar/How to cite}

Otamendi, María Alejandra (2020). La punitividad del público como reacción instrumental y expresiva ante las amenazas al comienzo del siglo XXI. Evidencias del Área Metropolitana de Buenos Aires. Revista CS, 31, 77-108. https://doi.org/10.18046/recs.i31.3720 


\section{Resumen}

Desde la psicología social con perspectiva sociológica, se indaga si la evolución de la demanda de mayores castigos hacia los delincuentes en la opinión pública, esto es, la punitividad pública, en el Área Metropolitana de Buenos Aires, entre los años 2000 y 2005, se vio afectada por las amenazas securitarias (hipótesis instrumental) o si fue, más bien, una reacción colectiva ante otro tipo de amenazas como las económicas, sociales y políticas que se canalizaron en una mayor hostilidad hacia los delincuentes (hipótesis expresiva). Con el fin de contrastar dichas hipótesis, se analizaron las ondas de la Encuesta de Victimización de la Dirección Nacional de Política Criminal. Se concluye que, si bien la reacción punitiva se corresponde relativamente a los niveles de amenaza securitaria, fue mayor aun cuando se politizó, en un sentido punitivo, en el espacio público (caso Blumberg), mostrando una respuesta tanto instrumental como expresiva.

\section{PALABRAS ClAVE:}

punitividad pública, opinión pública, castigo

From a sociological perspective of social psychology, this paper enquires whether the evolution of the demand for more severe punishment to offenders in public opinion (public punitiveness) in the Metropolitan Area of Buenos Aires between 2000 and 2005 was a reaction against security threats (instrumental hypothesis) or a collective reaction to other threats such as economic, social, and political insecurities that were channeled into a greater hostility towards criminals (expressive hypothesis). In order to test these hypotheses, the waves of the Victimization Survey of the National Division of Criminal Policy were analyzed. It was concluded that, although the punitive reaction corresponds relatively to the levels of criminal threat, it was even greater when it was politicized in a punitive sense in the public sphere (Blumberg case), showing that it was both an instrumental and an expressive response.

\section{KEYWORDS:}

Public Punitiveness, Public Opinion, Punishment 



\section{Introducción}

En las últimas décadas, el público en diferentes países y regiones ${ }^{1}$ incrementó sus demandas y reacciones sociales frente al delito. Dichas reacciones incluyen tanto la preocupación por el mismo como asunto público (reacción cognitiva macrosocial), la percepción de riesgo de victimización personal (reacción cognitiva microsocial) y el temor a ser víctima de la delincuencia (reacción afectiva microsocial), así como también demandas de mayores castigos hacia los delincuentes (reacción cognitiva macrosocial) acompañadas por diversas manifestaciones conductuales (reacción conductual microsocial) (Cullen; Fisher; Applegate, 2000; Hough; Roberts, 1999; 2005; LaGrange, 2003). Comprender dichas reacciones es relevante, ya que, como lo indica el Teorema de Thomas: "si los sujetos definen las situaciones como reales, éstas serán reales en sus consecuencias" (Elbert, 2007: 135).

Ciertamente, las interpretaciones de seguridad tienen efectos reales, tanto a nivel social como cambios conductuales para gestionar la (in)seguridad, el armamentismo, el vigilantismo, la segregación de ciertos grupos sociales y el debilitamiento de la cohesión social (Gamallo, 2017; Kessler, 2009; Míguez; Isla, 2010; Otamendi, 2016), así como económicos, en la distribución de recursos públicos y privados (Jaitman, 2017; Lorenc-Valcarce, 2011; Ronconi, 2009). A su vez, pueden influir en el endurecimiento del sistema penal, legitimando abusos policiales, restricciones a las garantías individuales y leyes penales más punitivas. Incluso pueden llevar a securitizar políticas sociales, erosionar la confianza en las capacidades estatales y en la democracia, impulsar la militarización de la seguridad interior y la adopción de medidas que atenten contra la libertad y los derechos humanos (Bateson, 2009; Chevigny, 2003; Sozzo, 2007; Stevens; Bishin; Barr, 2006; Tedesco, 200o; Tulchin; Fagan, 2003). En sociedades con legados autoritarios como las latinoamericanas, se vuelve entonces central estudiar el apoyo social que puede legitimar dichas prácticas y políticas.

En Argentina se sostiene que en los últimos años la sociedad se ha vuelto más punitiva, esto es, que demanda mayores castigos hacia los delincuentes, especialmente a partir de las masivas protestas organizadas por el empresario Juan Carlos Blumberg, a raíz del asesinato de su hijo secuestrado en 2004 (Masiva marcha..., 2004), lo cual impulsó varias leyes que incrementaron las penas para varios delitos (Calzado, 2011; Gutiérrez, 2011; Van den Dooren, 2011). En ese contexto, desde la

1. Para Gran Bretaña y Estados Unidos, ver Brown (2006), Garland (2005), Hope y Sparks (2000), y Pratt, Brown, Brown, Hallsworth y Morrison (2005). Para Francia, ver Muchielli (2008), Robert y Pottier (2004), y Roché (1998). Para América Latina, ver Chevigny (2003), Dammert y Salazar (2009), Kessler (2008), Smulovitz (2003), y Tedesco (2000), entre otros. 
psicología social con perspectiva sociológica, la presente investigación se plantea analizar las demandas de castigos más severos hacia los delincuentes, esto es, la punitividad pública como parte de las reacciones sociales ${ }^{2}$ hacia la (in)seguridad ${ }^{3}$ en el Área Metropolitana de Buenos Aires (AMBA). En particular, se pregunta si la demanda de mayor severidad penal fue una reacción instrumental ante mayores amenazas delictivas (hipótesis instrumental) o si fue más bien una reacción colectiva ante otro tipo de amenazas (económicas, sociales y políticas) que se canalizaron en una mayor hostilidad hacia los delincuentes (hipótesis expresiva). Con el fin de contrastar dichas hipótesis, se analizó la Encuesta de Victimización (EV) de la Dirección Nacional de Política Criminal (DNPC) (2000-2005). Con esta investigación se busca contribuir a una mayor comprensión de la punitividad pública en un contexto con legado autoritario, ya que en numerosas ocasiones la supuesta generalidad de demandas punitivas y de su conexión con el delito es tomada como aval de medidas y discursos represivos.

\section{Aproximaciones teóricas a la punitividad pública}

La demanda punitiva o punitividad pública como tendencia de la opinión pública que pide mayores castigos hacia los delincuentes es parte de lo que se denomina el giro punitivo o el populismo penal, donde las élites profesionales del sistema penal pierden relevancia en la formulación de las políticas penales, dando mayor lugar a las emociones y demandas del público, y en especial de las víctimas (Bottoms, 1995; Hallsworth, 2007). Esta tendencia de la política penal resulta de la estrecha interrelación entre los políticos, los medios de comunicación, el público general y diferentes grupos de interés (Garland, 2005; Roberts; Hough, 2005; Roberts; Stalans; Indermaur; Hough, 2003).

Dicha interrelación se puede dar a través de, por una parte, el populismo penal de arriba hacia abajo, donde políticos cínicos manipulan a la opinión pública ayudados por los medios de comunicación (Bourdieu, 2000; Champagne, 1990; Sartori, 1998) y ofrecen soluciones simples al delito como el aumento de penas (Matthews, 2005), ya sea porque no pueden o no quieren resolver otros problemas

\footnotetext{
2. Mientras que aquí se hace foco en un tipo de reacción cognitiva, en otros artículos se analizaron otro tipo de reacciones sociales hacia la inseguridad, comolas afectivas y las conductuales (Otamendi, 2014; 2016).

3. La inseguridad es una construcción social que puede definirse como la percepción de una amenaza a la integridad física que incluye solo algunos delitos, en particular, a los violentos, pero también a las llamadas incivilidades que no presuponen una infracción de la ley, sino de normas sociales (Kessler, 2009; LaGrange, 2003).
} 
más estructurales (Chevigny, 2003), porque les permite reproducir una estructura social desigual (Wacquant, 2005) o porque concentrarse en el delito es una estrategia eficaz de gobernabilidad (Simon, 2007) o de conseguir votos fácilmente (Green, 2009; Zimring; Johnson, 2006). Por otro lado, a través del populismo penal de abajo hacia arriba, donde un público ansioso y enojado presiona a los políticos a tomar medidas punitivas a través de los medios (Matthews, 2005), lo cual puede ser visto de forma positiva, como una mayor influencia democrática de la voz del público (Ryan, 2005), o de forma negativa, como la tiranía de la mayoría que impone, a través de encuestas y manifestaciones, sus deseos cambiantes a los medios y a los políticos (Rosanvallon, 2007).

En Argentina, cada uno de estos eslabones ya fueron analizados, tanto como populismo penal de abajo hacia arriba y viceversa, algunos destacando el rol de los familiares de víctimas como emprendedores morales, especialmente a raíz del caso Blumberg ya mencionado, pero también por protestas en ciudades medianas, y por otro tipo de delitos (Pita, 2011; Schillagi, 2009). Varios estudios se focalizaron en el rol de los medios de comunicación y la construcción de las noticias policiales (Calzado, 2015; 2018; Focás, 2017; Galar, 2018; Martini; Pereyra, 2009; Vilker, 2006); otros en los políticos, especialmente en campaña y en los legisladores, en particular en los debates legislativos sobre el incremento en el quantum de las penas como en el caso de las leyes Blumberg o sobre la ampliación de sectores a ser penalizados, por ejemplo, a través de la baja de edad de punibilidad (Annunziata; Mauro; Slipak, 2006; Calzado; Van den Dooren, 2009; Colombo, 2011; Guemureman, 2011; Gutiérrez, 2011); y, por último, varias investigaciones se centraron en los resultantes en la política penal, ya sea como aumento de los abusos policiales, la militarización de la seguridad interior, el incremento en la selectividad del sistema penal o el crecimiento exponencial de la población carcelaria como parte de la cadena punitiva (Daroqui, 2009; Daroqui; López, 2012; Kessler, 2009; Murillo, 2008; Otamendi; Zajac, 2019; Pegoraro, 2011; Rangugni, 2011; Rodríguez-Alzueta, 2014; Sozzo, 2007).

En la mayoría de estos estudios del contexto argentino, se da por sentado el consenso punitivo del público como uno de los eslabones del giro punitivo, aunque dicha idea ya fue cuestionada a partir del análisis de varias encuestas donde se muestra una mayoría preocupada y atemorizada, pero no necesariamente punitiva, aunque una minoría ruidosa sí lo sea (Otamendi, 2014; Sozzo, 2016). Menos frecuente aun es el estudio de factores macrosociales que afectaron la evolución de la demanda punitiva desde el análisis de la opinión pública4a . Este artículo propone

4. En este artículo, el nivel de análisis es macrosocial, es decir, la punitividad pública como tendencia de la opinión pública. En la tesis de doctorado y en otros artículos de mi autoría se analizan las actitudes punitivas a nivel individual, teniendo en cuenta el perfil sociodemográfico, las creencias y orientaciones 
abordar dicha temática desde la psicología social con perspectiva sociológica que sostiene que grandes cambios y problemas sociales como la delincuencia, pero también económicos y políticos tales como el desempleo, la desigualdad y el conflicto político, pueden ser percibidos como amenazas (Costelloe; Chiricos; Gertz, 2009; Hogan; Chiricos; Gertz, 2005; Rosenberg; Turner, 1992; Sales, 1973). Ante estas condiciones amenazantes, la punitividad del público hacia los delincuentes puede verse incrementada (Gerber; Jackson, 2012). Así, la demanda punitiva puede ser analizada a partir de diferentes enfoques agrupados en: hipótesis instrumental e hipótesis expresiva o simbólica (Haddock; Zanna, 1998; Jones; Newburn, 2006; Tyler; Boeckmann, 1997; Tyler; Weber, 1982).

Desde el enfoque instrumental, se parte de una visión de la pena como un instrumento de disuasión racional para potenciales delincuentes ${ }^{5}$ (prevención general negativa) o para evitar que los delincuentes sean reincidentes (prevención especial negativa) (Elbert, 2007; Sozzo, 2000). Se parte de la premisa de que el potencial delincuente es un actor racional que, a modo de homus economicus, sopesa costos y beneficios, esto es, penas y botines, y que en función de dicha ecuación decide racionalmente delinquir o no (Becker, 1968). Por lo tanto, la punitividad pública sería una reacción esperable ante el incremento de los niveles delictivos, a fin de que el aumento de penas demandado sea un instrumento de disuasión o prevención de futuros delitos. También se podría incluir aquí la reacción punitiva como deseo de venganza ante el aumento del delito, es decir, como una demanda de mayor severidad con un fin meramente retributivo, pero que sigue estando conectada a los vaivenes delictivos (Elbert, 2007).

Desde la mirada expresiva, se sostiene que la punitividad pública canaliza otro tipo de hostilidades y tensiones a través de la figura del delincuente. Así, se trataría de una reacción irracional o exagerada en relación al delito, que simboliza un desplazamiento de otros miedos, ansiedades y creencias (Roché, 1993). En ese sentido, Durkheim (2004) plantea que la verdadera función del deseo de venganza colectivo de la pena no es incrementar las penas para disuadir al agresor, sino mantener intacta la cohesión social, la conciencia colectiva a través de su dimensión afectiva. Tonko-

políticas, y las opiniones y experiencias con la (in)seguridad (Otamendi, 2012; 2013; 2015). Por tanto, la estrategia metodológica pertinente es el análisis de datos secundarios cuantitativos como las encuestas de victimización. Sin embargo, en un estudio posterior, se realizaron grupos focales para analizar con mayor profundidad las demandas punitivas hacia las distintas agencias del sistema penal, y las actitudes punitivas hacia distintos tipos de delitos y delincuentes con las propias palabras de las personas (Proyecto UBACYT 200201702O0181BA).

5. Sin embargo, la capacidad disuasiva de la pena ha sido fuertemente cuestionada, señalándose, en todo caso, su poder simbólico (Banco de Desarrollo de América Latina, 2014; Gutiérrez, 2011; Segato, 2003). 
noff (2011: 55), siguiendo a Durkheim, sostiene que "el vigor afectivo de la cuestión criminal se reactiva en épocas de in-diferenciación o falta de legibilidad de las fronteras y posiciones" o, en otras palabras, que la demanda punitiva se incrementa cuando los límites se vuelven borrosos en una sociedad diferenciada. Vinculado con esto, desde la teoría del etiquetamiento (Becker, 1971), se podría considerar a la demanda de mayores castigos hacia determinados actos y personas como la actualización de las reglas del grupo al etiquetarlos como desviados. De forma similar, Cohen (2002) denomina pánico moral a una reacción desproporcionada ante los actos de un grupo social considerado como enemigo común porque expresan una amenaza al orden social y a los valores compartidos (Ben-Yehuda, 2009).

Por su parte, desde la perspectiva del conflicto, se percibe el incremento de la reacción punitiva como un mecanismo de dominación mediante el cual los sectores privilegiados buscan controlar a los sectores populares que luchan por su ascenso e inclusión social (Jacobs; Carmichael, 2001; Johnson, 2009; Savelsberg, 1999). En este marco, el Estado neoliberal, mediante su aparato penal, cumple dicha función, reforzando la exclusión generada por el capitalismo (Wacquant, 2005). La demanda punitiva también puede estar canalizando las inquietudes de los sectores medios-bajos contra la amenaza que representan los sectores populares al propio estatus, buscando diferenciarse y expresar el resentimiento que les generan los beneficiarios de la asistencia social (Young, 2007). Así, la punitividad pública sería una reacción social que expresa las ansiedades del conflicto social, más que una respuesta instrumental al delito, tema ya analizado para el AMBA en un estudio previo (Otamendi, 2015).

En términos más generales, se postula que ante los riesgos ambientales, laborales y financieros de la modernidad tardía, se incrementaron los sentimientos de ansiedad e inseguridad en toda la sociedad, debilitando los lazos de solidaridad e identificación mutua, dando lugar a una mayor demanda punitiva hacia el delincuente como enemigo fácilmente identificable y como demanda hacia el Estado para fortalecer su autoridad percibida en crisis y devolver cierto orden a un mundo caótico y peligroso (Beck, 1998; 2008; Castel, 2004; Dubet, 2002; 2016; Garland, 2005; Giddens, 1991). Ante esta situación de amenaza constante e incontrolada, y dado el debilitamiento de las certezas que permitían una mayor tolerancia a las diferencias y a los riesgos, se llegaría a un menor autocontrol individual, dando rienda suelta a las emociones, al miedo y a la rabia. Así, la sensibilidad social que se había civilizado durante la modernidad y que había tenido como consecuencia la reducción de la severidad de las sanciones (Elias, 1993), se volvió más emotiva, mientras demandaba y habilitaba una mayor punitividad en el ámbito de la justicia, como parte de un proceso decivilizatorio (Pratt, 2005). 
Así, pueden coexistir varias de las amenazas mencionadas, dando lugar a un incremento de la reacción punitiva, tal como sucede en Argentina a comienzos del siglo XXI. En efecto, en el inicio del segundo milenio, subsisten allí las consecuencias económicas, políticas y sociales de diferentes procesos históricos como la dictadura militar de 1976 a 1983, la crisis de hiperinflación de los ochenta, las reformas neoliberales de los noventa, y su consecuente crisis económica, política y social de 2001, dando lugar a una considerable fragmentación económica, social y política (Rapoport, 2005). De esta manera, varios de los factores señalados como impulsores de la punitividad pública se encuentran presentes en dicho contexto. Por lo tanto, en este artículo se busca poner a prueba las hipótesis instrumental y expresiva de la punitividad pública en el ámbito del AMBA durante los primeros años del segundo milenio, esto es, se busca analizar si la evolución de la demanda por mayores castigos hacia los delincuentes, en la opinión pública, se vio afectada por la evolución de los niveles delictivos o más bien expresa reacciones desplazadas de otro tipo de amenazas que se canalizaron en el delincuente.

Se eligió el AMBA porque es el área con mayor nivel de delito -por ejemplo, en 2002 concentró el $50 \%$ de los homicidios de todo el país (Sistema Nacional de Información Criminal [SNIC], 2003)-y es donde han ocurrido el secuestro y asesinato de Axel Blumberg, y las mayores protestas y demandas legales, ya que es el centro político-administrativo nacional (sede de los tres poderes) y, por lo tanto, desde allí parten las leyes y políticas de seguridad para todo el país. Asimismo, convive alrededor de un tercio de la población del país, por lo que tiene un alto peso electoral, lo cual conlleva que los casos policiales que allí suceden puedan cobrar considerable relevancia política y mediática con proyección nacional. Además, el AMBA fue la única área revelada en todas las ondas de la EV de la DNPC, existiendo solo dos encuestas nacionales en 2010 y 2017, aunque esta última no incluye indicadores de punitividad.

De igual manera, se decidió focalizar en el período 2001-2005 por razones tanto sustantivas como prácticas: en primer lugar, como se señaló, en 2001 se produjo una de las mayores crisis económicas, sociales y políticas de la historia argentina, dejando altos niveles de desocupación, pobreza, desigualdad y también conflictividad social y política, los cuales pudieron actuar como disparadores de una mayor punitividad pública (Palomino, 2004). Luego, en 2002 se dio el pico de homicidios dolosos en Argentina, alcanzando la tasa de 9,5 a nivel nacional y de 15 homicidios por cada 100 ooo habitantes en el AMBA (SNIC, 2003), lo cual también pudo impulsar la demanda de mayores penas. Por último, como se mencionó, en 2004 se produjo el secuestro y luego asesinato de Axel Blumberg, lo cual empujó a su padre, un empresario de la zona norte del Gran Buenos Aires (GBA), a convocar a una de las mayores protestas durante el regreso de la democracia en Argentina, la firma 
masiva de un petitorio con varias medidas punitivas, y el tratamiento y aprobación de forma express de leyes que incrementaban las penas para varios delitos (Gutiérrez, 2011). Así, en este período se dieron grandes amenazas de distintos tipos que pudieron haber impactado en la evolución de la demanda punitiva, generando efectos más observables que durante momentos de mayor normalidad ${ }^{6}$ (Van Evera, 2002). Además, se tomaron estos años también por razones prácticas, ya que solo la EV de este período incluye al menos dos indicadores de demanda punitiva.

\section{Estrategia metodológica}

Como se anticipó, para analizar la punitividad pública se tomaron las bases de datos de la EV7 de la DNPC del Ministerio de Justicia y Derechos Humanos de la Nación (olas 2001, 2002, 2003 y 2005) ${ }^{8}$. Cada ola se refiere a la victimización ocurrida durante ese año; así, si bien el trabajo de campo se realizó a principios del año siguiente, se pregunta por lo ocurrido en los doce meses anteriores. Por lo tanto, la EV 2003 se llevó a cabo durante el año 2004, en pleno apogeo de las marchas Blumberg, captando justo un momento de alta conflictividad político-social. Estas encuestas fueron realizadas siguiendo un muestreo probabilístico por conglomerados de etapas múltiples con selección de la unidad final de acuerdo a cuotas de edad y sexo a residentes de 15 años y más de la Ciudad Autónoma de Buenos Aires (CABA) y de los 24 partidos del Gran Buenos Aires (GBA) que conforman el AMBA (ver Cuadro 3 en Anexo para otras características de la muestra). Se trata de una encuesta domiciliaria que utiliza una versión adaptada del cuestionario UNICRI (Sozzo, 2003).

En cuanto a los indicadores seleccionados para medir punitividad pública, Cullen et al. (200o) advierten que no existe un diseño que logre abordar su complejidad,

6. De todas maneras, en la tesis de doctorado (Otamendi, 2013), con otra fuente de datos (LICIP), se abarca un período más normal en términos de amenazas securitarias, económicas, políticas y sociales, que es la segunda mitad de la década del 200o. En esos años, hay mayor correspondencia entre amenaza securitaria y demanda punitiva, aunque esta última es aún mayor en el año 2008, probablemente expresando también el malestar político por el conflicto entre el gobierno y el sector agropecuario. Se corrobora la hipótesis instrumental, aunque también la expresiva, en este año, manifestando otros malestares sociales.

7. En otro trabajo (Otamendi, 2013), se analizaron todas las encuestas disponibles para la Argentina que contaran con algún indicador de actitud punitiva, tales como la que aquí se analiza (DNPC), las de las universidades de San Andrés (UDESA) y de Torcuato Di Tella (UTDT), y las internacionales como Latinobarómetro, Gallup y Barómetro de las Américas (LAPOP).

8. Lamentablemente, no existe ola 2004, ya que no se llevó a cabo el relevamiento correspondiente a comienzos del año 2005, aunque para sintetizar, se hará referencia al período 2001-2005. 
por lo que recomiendan considerar de manera conjunta las tendencias que surgen a partir de los diversos estudios sobre el tema. Aquí se siguió el mismo criterio, de manera tal que no se partió de una operacionalización acabada de la punitividad pública, sino que se relevaron los indicadores utilizados en Argentina y se identificaron las dimensiones teóricas subyacentes. Una primera distinción se da entre las orientaciones generales y específicas hacia el castigo de los delincuentes. Por las primeras se entienden las visiones generales de los ciudadanos sobre el castigo, donde se estudian las creencias más abstractas o globales sobre las penas (Applegate; Cullen; Turner; Sundt, 1996; Rossi; Berk, 1997). Cullen et al. (2000) consideran que así se están midiendo actitudes generales que las personas tienen sobre determinadas políticas, pero no sobre casos concretos en que dicha política debería ser aplicada (actitudes específicas). En estas últimas, la persona debe orientar su actitud en función de los detalles y de la información disponible sobre hechos delictivos particulares (King; Maruna, 2009). Así, estos dos tipos de orientaciones refieren a dos planos de análisis, el primero remite a una dimensión política, al registro de la moral, los valores y las normas (Roché, 1998); el segundo, más concreto y personal, remite a una dimensión más conductual, donde el selfse encuentra más involucrado y tiene una mayor responsabilidad sobre un otro individualizado al que se le aplicaría la pena; ego-involvement, según Schuman y Presser (1996: 231).

Teniendo en cuenta la disponibilidad de datos para los análisis posteriores, este trabajo se focalizó en dos indicadores ${ }^{9}$ : uno general, como la preferencia de medidas más punitivas para reducir la inseguridad; y uno más específico, como la preferencia de penas más severas para un hecho concreto (tal como se muestra en el Cuadro 4 y Cuadro 5 del Anexo) ${ }^{10}$. A partir del cruce de ambos indicadores, se construyó la siguiente tipología de tipos punitivos ${ }^{11}$ :

9. En un estudio previo se analizaron varios indicadores de cada orientación y se construyeron medidas complejas (Otamendi, 2013).

10. Una limitación del instrumento de recolección y de todas las encuestas analizadas previamente (Otamendi, 2013) es que no miden las actitudes punitivas ante distinto tipo de delitos y de delincuentes, sino solo ante una situación específica de robo de un televisor en el hogar por un joven reincidente, tal como se detalla en el Anexo. De todas maneras, este indicador es el más utilizado a nivel internacional y se desprende del cuestionario modelo de UNICRI (Sozzo, 2003). Además, como se mencionó en otra nota, en un proyecto posterior se analizaron, a través de grupos focales, las actitudes punitivas hacia distintos tipos de delitos y de delincuentes.

11. Si bien se trata de una tipología teórica, en la tesis se realizaron pruebas empíricas como el Análisis de Correspondencia Múltiple (ACM), donde las categorías estipuladas teóricamente como afines, aparecían cercanas: en un polo más punitivo se aproximaban medidasnegativas y pena de prisión, y en el polo opuesto, otro tipo de medidas y de penas (Otamendi, 2013). 
- No punitivistas: optan por medidas no negativas para mejorar la seguridad y, ante un caso hipotético de un ladrón reincidente, prefieren penas alternativas a la prisión.

- Punitivos específicos: si bien no plantean medidas preventivas negativas para mejorar la seguridad, sí creen que un ladrón reincidente debe ir a la cárcel.

- Punitivos generales: consideran que un aumento general en las penas mejoraría la seguridad, pero no aplicarían la pena de prisión para un caso concreto de robo.

- Punitivos complejos: además de proponer medidas de prevención punitivista negativa para reducir la inseguridad, sostienen que se debe penar con la cárcel a un ladrón reincidente.

Luego, se seleccionaron los indicadores para medir cada amenaza que pudiera afectar la demanda punitiva (ver Cuadro 1):

CUADRO 1 Indicadores utilizados para medir diferentes amenazas macrosociales

\section{Tipo de amenaza $\mid$ Indicador | Medición | Fuente}

Securitaria Nivel de delito

Tasa de homicidios dolosos

Sistema Estadístico de Salud

(SES), Ministerio de Salud

(2001-2005)

\begin{tabular}{|c|c|c|c|}
\hline & & & \\
\hline Securitaria & Nivel de delito & $\begin{array}{l}\text { Porcentaje de } \\
\text { victimización: } \\
\text { - General } \\
\text { - Contra la propiedad } \\
\text { - Violenta }\end{array}$ & $\begin{array}{l}\text { Encuesta de Victimización } \\
\text { (EV), Dirección Nacional } \\
\text { de Política Criminal DNPC, } \\
\text { Ministerio de Justicia y } \\
\text { Derechos Humanos de la } \\
\text { Nación }\end{array}$ \\
\hline
\end{tabular}

\begin{tabular}{|c|c|c|c|}
\hline Económica & $\begin{array}{l}\text { Nivel de } \\
\text { desocupación }\end{array}$ & Tasa de desocupación & \multirow{2}{*}{$\begin{array}{l}\text { Encuesta Permanente de } \\
\text { Hogares (EPH), Instituto } \\
\text { Nacional de Estadística y } \\
\text { Censos (INDEC) }\end{array}$} \\
\hline Social & Nivel de pobreza & $\begin{array}{l}\text { Porcentaje de hogares bajo } \\
\text { la línea de pobreza }\end{array}$ & \\
\hline \multirow{2}{*}{ Política } & $\begin{array}{l}\text { Existencia de } \\
\text { elecciones }\end{array}$ & \multicolumn{2}{|c|}{$\begin{array}{l}\text { - Legislativas }(14 \cdot 10.2001) \\
\text { - Presidenciales y legislativas }(27.04 .2003) \\
\text { - Legislativas }(23.10 .2005)\end{array}$} \\
\hline & $\begin{array}{l}\text { Conflictos } \\
\text { políticos }\end{array}$ & \multicolumn{2}{|c|}{$\begin{array}{l}\text { - Crisis política (diciembre de 2001) } \\
\text { - Blumberg (abril de 2004) }\end{array}$} \\
\hline
\end{tabular}


Como se observa en el Cuadro 1, la amenaza securitaria se midió a partir de varios indicadores: primero, la tasa de homicidios dolosos cada 100 ooo habitantes, a partir de las muertes por agresiones y por intención no determinada con armas de fuego ${ }^{12}$ en las bases de datos de las muertes por causas externas que compila a nivel nacional el Ministerio de Salud de la Nación. Luego, como los homicidios son fenómenos poco frecuentes, se incluyeron otras medidas de amenaza securitaria, pero que no dependieran del nivel de denuncia, que es bajo, sino del nivel de declaración en la EV de la DNPC, que es más alta. A partir de las respuestas positivas a un grupo de preguntas sobre la experiencia de victimización de algún miembro del hogar encuestado, se construyeron tres indicadores de victimización: 1) general, 2) contra la propiedad, y 3) violenta (ver Cuadro 6 en el Anexo). Para los indicadores de la amenaza económica (nivel de desocupación) y social (nivel de pobreza) se recurrió a la Encuesta Permanente de Hogares (EPH) que elabora el Instituto Nacional de Estadística y Censos (INDEC), seleccionando la onda que coincidía con el relevamiento de la EV de la DNPC. Por último, para las amenazas políticas, se tuvieron en cuenta tanto los períodos electorales donde las campañas políticas podían politizar la seguridad y afectar la demanda punitiva, como los conflictos políticos más intensos, uno general, como la crisis de 2001, y otro vinculado a la seguridad, como el ya mencionado de Blumberg.

\section{Análisis: punitividad pública y amenazas en el AMBA (2001-2005)}

Para analizar la incidencia de las diferentes amenazas en la punitividad pública se trató, de forma exploratoria, tipos punitivos como variable intervalar que va de 1 (no punitivos), pasando por 2 (punitivos específicos), a 3 (punitivos generales) y finalmente a 4 (punitivos complejos). Como lo muestra el Cuadro 2, se analizó su nivel de correlación con los indicadores de los diferentes tipos de amenazas. Allí se observa que el nivel promedio de punitividad pública es de alrededor de 2 puntos, lo que muestra un nivel intermedio de demanda punitiva, alejándose de la idea de consenso punitivo. Esto coincide con la moda que señala que el tipo punitivo más frecuente es el de los punitivos específicos, quienes, si bien enviarían a la cárcel a un ladrón reincidente, no consideran que el aumento de penas ni la pena de muerte sean medidas eficaces para reducir el delito. En este sentido, el castigo sería visto como un fin en sí mismo, pero no como medio para la disuasión.

12. Se agrupan estas dos categorías para dar cuenta del conjunto de los homicidios (Fleitas; Otamendi, 2007). 
\begin{tabular}{l|l} 
CUADRO 2 & Medidas descriptivas y correlaciones bivariadas de las amenazas con el
\end{tabular} nivel de punitividad pública, AMBA (2001-2005)

\begin{tabular}{|c|c|c|c|c|}
\hline $\begin{array}{c}\text { Tipo de } \\
\text { amenaza }\end{array}$ & Indicadores & Media & $\begin{array}{l}\text { Desvío } \\
\text { estándar }\end{array}$ & $\mathbf{r}$ \\
\hline & Nivel de punitividad pública & 1,9 & 0,1 & $1, \mathrm{ooo}$ \\
\hline \multirow{4}{*}{ Securitaria } & Porcentaje de victimización general & 38,1 & 4,2 & $0,499^{*}$ \\
\hline & $\begin{array}{l}\text { Porcentaje de victimización contra } \\
\text { la propiedad }\end{array}$ & 29,2 & 3,3 & $0,556^{*}$ \\
\hline & $\begin{array}{l}\text { Porcentaje de victimización } \\
\text { violenta }\end{array}$ & 13,4 & 2,2 & $0,612^{*}$ \\
\hline & $\begin{array}{l}\text { Tasa de homicidios dolosos cada } \\
\text { 10o ooo habitantes }\end{array}$ & 13,5 & 4,9 & 0,495 \\
\hline Económica & Tasa de desocupación por semestre & 16,4 & 4,7 & 0,353 \\
\hline Social & $\begin{array}{l}\text { Porcentaje de hogares bajo la línea } \\
\text { de pobreza }\end{array}$ & 29,1 & 14,7 & $0,586^{*}$ \\
\hline
\end{tabular}

$\mathrm{Al}$ analizar cómo se vincula cada amenaza con el nivel de punitividad pública, se observa que la victimización violenta es la que más está correlacionada $(r$ de Pearson $0,612) \mathrm{y}$, en menor medida, pero igualmente de forma significativa, la victimización contra la propiedad y la victimización general ( $r$ de Pearson 0,556 y 0,499, respectivamente). Estos resultados coinciden con los obtenidos a partir de la Encuesta LICIP en el AMBA, entre los años 2006 y 2009, donde los niveles de victimización violenta afectaron la demanda punitiva en mayor medida que la victimización contra la propiedad y que la victimización general (Otamendi, 2012). Esto se debe a que la experiencia de victimización violenta opera en la redefinición de la situación, genera estrés postraumático y mayores impactos en las percepciones, afectando incluso las creencias y valores más profundos como las orientaciones hacia el castigo (Kühnrich; Kania, 2005; Roberts; Hough, 2005; Sprott; Doob, 1997). En otros estudios se llegó a resultados similares, siendo las víctimas de delitos con contacto con los delincuentes más punitivos que las de delitos sin contacto, despejando la llamada paradoja de la victimización que se había encontrado en estudios previos, donde las víctimas no eran necesariamente más punitivas o temerosas al delito (Bergman; Kessler, 2008; Kessler, 2011; Rountrée, 1998). 
No obstante, el nivel de homicidios no pareciera generar mayor punitividad del público. Este hallazgo también va en sintonía con los resultados de un estudio regional donde la experiencia más directa con el objeto de la actitud, como sucede en la victimización personal, tiene mayores efectos en las distintas reacciones sociales de (in)seguridad, tales como el temor al delito, la preocupación securitaria y la demanda punitiva que los niveles de homicidios que ocurren en menor proporción y de manera más indirecta, como presión ecológica del delito (Otamendi, 2016). Por último, entre las amenazas no securitarias se registra cierto efecto de los niveles de pobreza en la demanda punitiva, alimentando la hipótesis expresiva de la punitividad pública como muestra de otro tipo de malestares sociales que se canalizan en una mayor hostilidad hacia el delincuente como cara visible. A continuación, se analizarán con mayor profundidad estos primeros resultados, a partir de análisis de regresión y de la inclusión de las amenazas políticas.

\section{Amenaza securitaria y demanda punitiva}

Como era de esperar, a partir del diagrama de dispersión (ver Figura 1), se observa una relación lineal positiva entre el porcentaje de victimización violenta y el nivel de punitividad en la muestra relevada en cada año y unidad geográfica, de manera tal que mediante este modelo se explicaría el 37,5\% de su variabilidad. Así, a medida que se incrementa en un punto porcentual la cantidad de encuestados victimizados violentamente, el nivel de punitividad aumenta en o,026 puntos (beta no estandarizada).

Resulta de interés analizar los casos que se alejan de la recta de regresión: por debajo, se encuentran los tres distritos, en 2002, y la CABA, en 2001. Como lo muestra la figura, el año 2002 fue de alto nivel de victimización violenta, lo que se puede constatar, además, por el pico en la tasa de homicidios dolosos y de delitos, como ya fue mencionado (Fleitas; Otamendi, 2007; SNIC, 2002). Sin embargo, el nivel de punitividad para todos los distritos en 2002 está por debajo de la recta de regresión. En efecto, el incremento en el delito en dicho año no se vio inmediatamente reflejado en una mayor reacción punitiva de forma proporcional. Probablemente otros problemas como la alta desocupación, la inestabilidad política y los altos niveles de pobreza resultantes de la crisis de fines de 2001 desplazaron la atención de la amenaza delictiva (ver Figura 2).

Tal como se percibe en la Figura 2, el nivel de preocupación por la seguridad, es decir, el porcentaje de encuestados que la consideran como el principal problema del país, era de tan solo 5,8 \%, muy por debajo en comparación al 43,1 \% que priorizaba el problema del desempleo en el AMBA, más aún si se considera que el año 2002 registró el pico de homicidios y delitos (Latinobarómetro, 2000-2009. De forma 

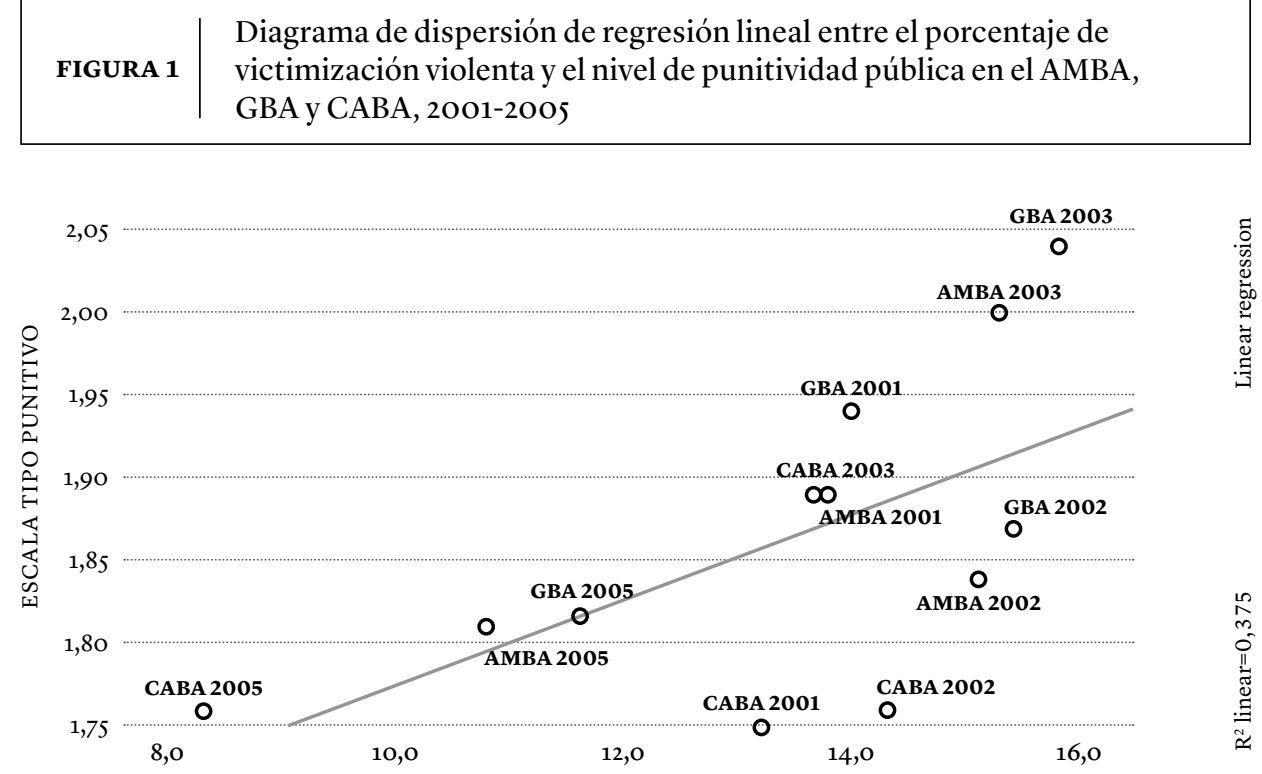

PORCENTAJE DE VICTIMIZACIÓN VIOLENTA

Fuente: elaboración propia a partir de DNPC (2001-2005). Se incluyó el AMBA para visualizar los valores promedio.

\begin{tabular}{l|l} 
FIGURA 2 & $\begin{array}{l}\text { Niveles de preocupación securitaria y laboral como principal problema, } \\
\text { AMBA (2000-2009) }\end{array}$
\end{tabular}

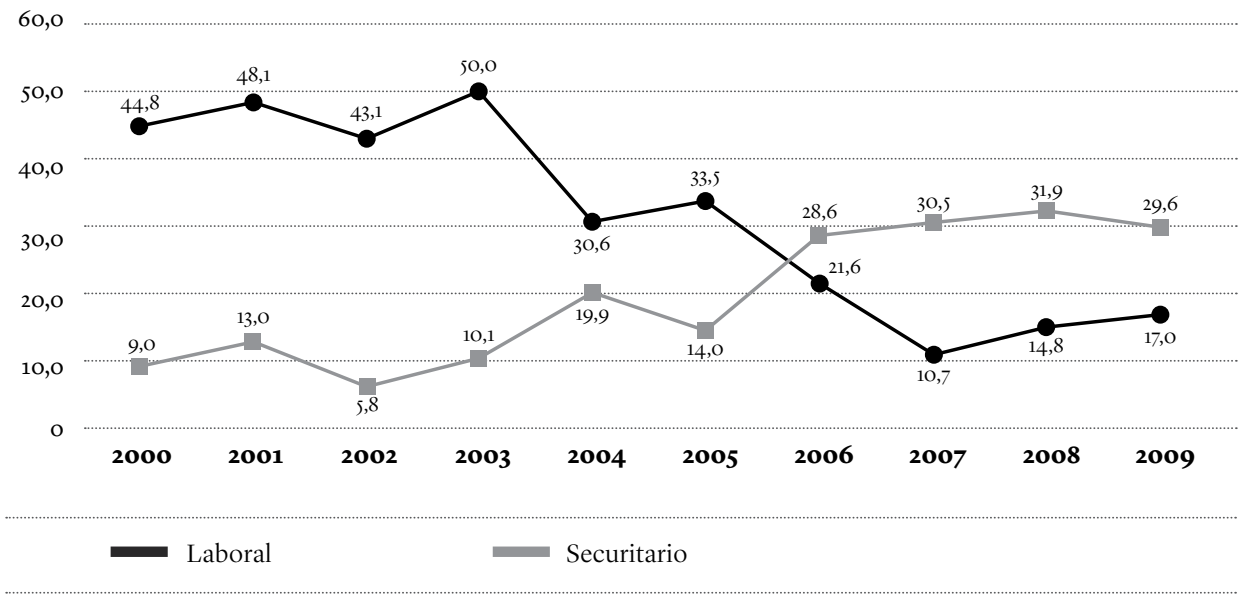


paradójica, la preocupación securitaria se incrementó hasta su pico en 2004, cuando el delito se encontraba en retroceso, pero coincidía con las protestas de Blumberg en las calles. Sin embargo, esto puede deberse a la reducción en los niveles de desempleo por la recuperación económica y, por lo tanto, a la menor preocupación por la cuestión laboral que alcanzó su mínimo al 30,6\% de los encuestados del AMBA en 2004 (Latinobarómetro, 2000-2009). Luego, desde el año 2006 la seguridad pasó a ser la principal preocupación en el AMBA. Sin llegar a ser mayoritaria, la seguridad desplazó a otras preocupaciones, aun cuando los niveles de delito se redujeron al menos hasta el año 2007 (SNIC, 2008).

Estos resultados algo paradójicos también se encontraron a nivel regional (Otamendi, 2016), donde países con altos niveles delictivos tenían niveles de preocupación securitaria mucho menores que otros con menores índices, probablemente también por una mayor preocupación por problemas sociales. Como lo señala Douglas (1992), el proceso de selección de riesgos es una operación intersubjetiva que hace intervenir a las creencias y valores, respondiendo a una lógica cultural e identitaria. Por lo tanto, de todos los riesgos posibles, solo algunos son seleccionados como preocupaciones principales a nivel social.

Retomando el análisis de la Figura 1, se observa que, al contrario, por encima de la recta se encuentran todos los distritos durante el relevamiento de 2003 , hecho en abril de 2004. Esto muestra que, si bien el porcentaje de victimización violenta fue elevado en 2004, la reacción punitiva fue mucho más alta de lo que la tendencia indicaba. Cabe recordar que dicho incremento en la punitividad pública por encima de la tendencia coincide con el apogeo de los reclamos de Blumberg en los medios y las calles. Ambos desvíos muestran que el grado de victimización violenta afecta los niveles de punitividad pública, y que otros factores pueden restar o sumar fuerzas a dicha reacción punitiva. Por un lado, otros problemas graves, como un alto nivel de desocupación y pobreza para un determinado nivel de delito, morigerarían la reacción punitiva. Por otro lado, la politización y tematización de la inseguridad como sucedió durante el auge del reclamo de Blumberg-podrían estar explicando un incremento de la reacción punitiva por encima de los niveles de victimización violenta. Así, la amenaza delictiva aparece como una condición necesaria para el incremento de la reacción punitiva, pero no suficiente, mostrando relativa autonomía.

Lo mismo se puede señalar si, en lugar de tomar el porcentaje de victimización violenta, se tiene en cuenta la tasa de homicidios dolosos, como se observa en el siguiente diagrama de dispersión (ver Figura 3). Allí se muestra que las tasas más altas se produjeron en 2002, pero no así las mayores reacciones punitivas. Al contrario, en 2001, pero especialmente en 2003 (relevamiento hecho en 2004), la reacción punitiva es superior a la que le correspondería según los niveles de homicidios dolosos. Así, 
el año más violento, 2002, no muestra la mayor punitividad pública, y sí lo hace el año 2004, cuando los homicidios son menores. Luego, en 2005, se reducen tanto los niveles de homicidios dolosos como la reacción punitiva, ajustándose mejor a la recta. De todas formas, como se informó en el Cuadro 2, la relación no es significativa.

En los dos diagramas de dispersión anteriores (ver Figura 1 y Figura 3), se observa que en cada año la Ciudad Autónoma de Buenos Aires es menos punitiva que el Área Metropolitana de Buenos Aires, en general, y menos aún que el Gran Buenos Aires, en particular. Si bien esto sigue la tendencia delictiva, en términos generales, es decir, que en la CABA el nivel de delito violento es menor que en el GBA en todos los años y, por lo tanto, es de esperarse un menor nivel de punitividad pública, dichas distancias no son proporcionales. En efecto, mientras el GBA es cada vez más violento que la CABA, según el porcentaje de victimización violenta, ya que pasa de superarla en un 6,1 \% en 2001 hasta un 39,8 \% en 2005, la diferencia en el nivel de punitividad se achica: pasa de superarla en 10,9\% en 2001, a superarla tan solo por el 3,4\% en 2005. Por lo tanto, si bien todos los años en la CABA se muestran menos punitivos que en el GBA, en el relevamiento de 2003 y, más aún, en el de 2005, los porteños encuestados son proporcionalmente más punitivos, si se tiene en cuenta su menor nivel de victimización violenta.

\begin{tabular}{|l|l|}
\hline FIGURA 3 & $\begin{array}{l}\text { Diagrama de dispersión de regresión lineal entre la tasa } \\
\text { de homicidios y el nivel de punitividad pública en el AMBA, GBA } \\
\text { y CABA (2001-2005) }\end{array}$ \\
\hline
\end{tabular}

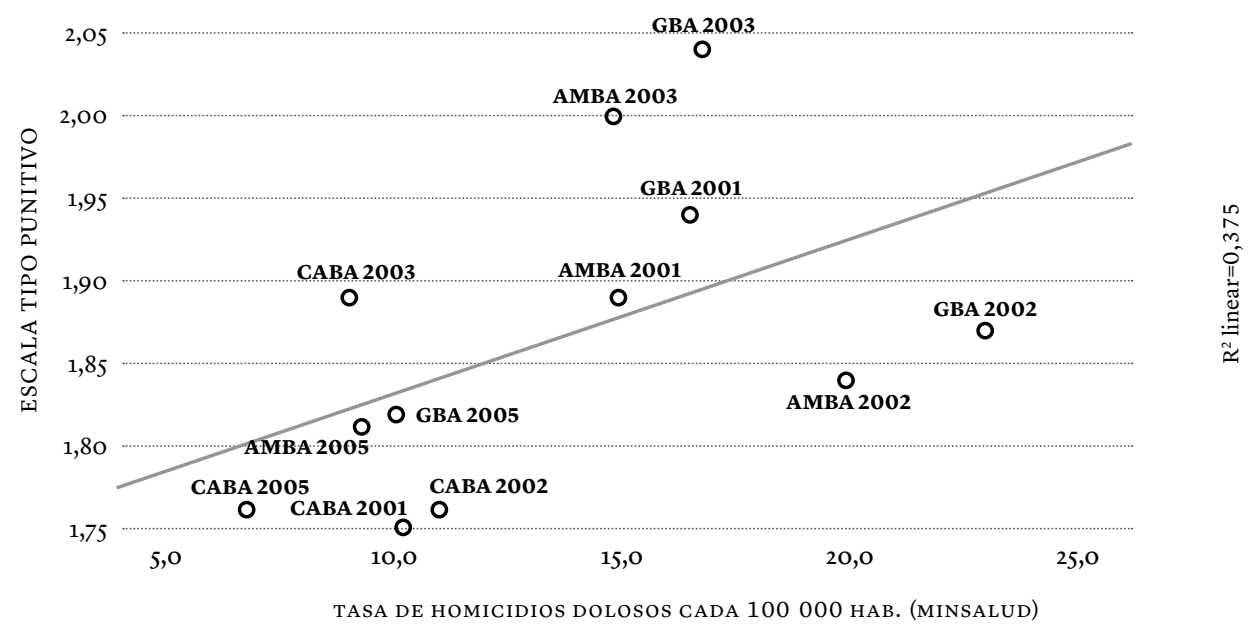




\section{Otras amenazas y punitividad pública}

Retomando las diferentes amenazas (ver Cuadro 2), además del porcentaje de victimizados, la amenaza social también pareciera estar asociada con los niveles de punitividad pública, esto es, el porcentaje de hogares bajo la línea de la pobreza, donde a mayor pobreza, mayor punitividad pública ( $r$ de Pearson de o,586 con un $\mathrm{p}$ de o,023). Sin embargo, al incluir tanto los niveles de victimización violenta como de pobreza en un análisis de regresión lineal múltiple, solo la amenaza delictiva incide significativamente sobre el nivel de punitividad pública. Por lo tanto, no habría relación directa entre dicha pobreza y la punitividad pública, aunque sí entre la victimización violenta y la punitividad pública, como ya se demostró.

Así, es más bien la amenaza delictiva especialmente violenta la que incide en la punitividad pública entre 2001 y 2005, y no tanto otro tipo de amenazas como las sociales o económicas. Incluso si se toman en cuenta las posibles amenazas políticas de entonces, como pudo haber sido la campaña por las elecciones presidenciales y legislativas del 27 de abril de 2003, que coincidieron con el relevamiento de 2002, tampoco la amenaza política pareciera haber incidido en dicho año. Esto puede deberse a que ni la campaña triunfante de Néstor Kirchner ni la derrotada de Carlos Menem tuvieron como eje de disputa a la inseguridad. De esta manera, la inseguridad no pasó a electoralizarse y, por lo tanto, pareciera no haber incidido en los niveles punitivos en dicho año (Sozzo, 2007).

Sin embargo, a partir de la presencia de Blumberg en el espacio público, en 2004, la reacción punitiva excedió al nivel de amenaza delictiva, incluso cuando dichos datos son tenidos en cuenta. Esto se observó en los diagramas de dispersión al tener en cuenta los niveles de victimización violenta y de homicidios dolosos, ya que, si bien su pico fue en el año 2002 en todos los distritos, los niveles de punitividad pública fueron aún mayores en la onda de 2003 (hecha en 2004) para menores niveles de homicidios y de victimización violenta. En otras palabras, la amenaza delictiva estimuló la reacción punitiva en la CABA, el GBA y el AMBA, en general, entre 2001 y 2005, pero a partir del efecto Blumberg, en 2004, que se podría considerar como la politización de la amenaza delictiva en un sentido punitivo, dicha reacción punitiva superó a los niveles de amenaza delictiva.

\section{Conclusiones}

La demanda de mayores castigos hacia los delincuentes en la opinión pública, fenómeno conceptualizado como punitividad pública, es considerada uno de los eslabones del llamado giro punitivo o populismo penal, tanto de abajo hacia arriba, donde 
el público presiona a los políticos a tomar medidas punitivas a través de protestas y de los medios de comunicación, como de arriba hacia abajo, donde los políticos manipulan a la opinión pública a través de los medios para impulsar una agenda punitiva que les permita mayor control y desviar la atención de otros problemas. A su vez, dicha demanda punitiva del público puede ser una reacción instrumental ante los incrementos del delito, siendo la pena un medio para la disuasión y prevención de futuros delitos o, al menos, teniendo un fin retributivo en sí mismo. También puede responder a otros tipos de amenazas macrosociales que se traducen en una mayor hostilidad hacia el delincuente como cara visible de un enemigo construido socialmente, aun cuando el delito se encuentre en caída.

En este artículo, a partir de una tipología de tipos punitivos, se analizó el posible efecto que diferentes amenazas podrían haber tenido en su evolución en la primera mitad de la década del 2000 en el Área Metropolitana de Buenos Aires. Primero, se observó que en promedio la demanda del público es específica, esto es, que mandarían a la cárcel a un ladrón reincidente de un hecho de robo, pero no consideran que el aumento de penas o la pena de muerte sirvan para reducir el delito. Es decir, se entiende la pena como fin retributivo, pero no necesariamente como medida de prevención o disuasión. En cuanto a la evolución de la demanda punitiva, se observó que ante el incremento de la amenaza securitaria, para 2002, no se produjo una inmediata respuesta punitiva generalizada. En efecto, cuando se dio el pico de homicidios y de victimización violenta, la preocupación securitaria y la demanda punitiva eran aún minoritarias. Así, la respuesta punitiva no fue mecánica, ya que en ese momento otros riesgos eran vistos como más preocupantes, tales como la desocupación o la inestabilidad política y económica. Una vez que estos fueron percibidos como menos amenazantes, otros riesgos fueron cobrando mayor importancia, como el securitario, incluso cuando la amenaza delictiva estaba en descenso. Esto responde a la operación intersubjetiva señalada por Douglas (1992), donde, de todos los riesgos posibles, solo algunos son seleccionados como preocupaciones principales en un contexto determinado.

Luego, dichos riesgos seleccionados de manera colectiva son interpretados culturalmente y provistos de diferentes respuestas legítimas en dicho contexto. Así, la inseguridad como preocupación principal fue politizada en términos más punitivos durante los reclamos organizados en torno al secuestro y la muerte de Axel Blumberg, en el año 2004. En dicho caso, el enemigo privado, esto es, el secuestrador, se transformó en un enemigo público generalizado a través de la movilización política y social generada por su padre: el pasaje de lo micro a lo macro se produjo, entonces, a través de la politización del discurso privado, logrando que el público se identificara con la víctima individual y así se transformara en una víctima colectiva (Cohen, 2002; Garland, 2005; Roché, 1993: 260). 
Por lo tanto, se concluye que el incremento en la punitividad pública no fue solo instrumental, como reacción ligada estrictamente a la inseguridad; pero tampoco solo simbólica, como expresión y desplazamiento de otras ansiedades, sin relación con los niveles delictivos. Al menos en el AMBA, la demanda punitiva respondería a una experiencia colectiva de inseguridad, por lo que no sería pánico moral, ya que hay una realidad del delito (Lea; Young, 2001) experimentada de manera directa $\mathrm{e}$ indirecta por las personas encuestadas (Roché, 1993). Pero, al mismo tiempo, tampoco sería una reacción puramente mecánica, sino que respondería a la politización del fenómeno en dichos términos, a la experiencia mediada discursivamente a partir de los recursos simbólicos presentes en determinado momento histórico.

Como lo señala Garland (2002: 59), la punitividad pública no deriva de legados culturales inalterables, sino que "son disposiciones que son creadas, reproducidas o transformadas en el contexto de relaciones de grupos, que cambian cuando las estructuras de la competencia económica y del conflicto político cambian, y que están afectadas por eventos y luchas específicas". En este sentido, una vez que la inseguridad se politiza de manera punitiva, como en 2004, legitima un modo de entender y responder al fenómeno delictivo que luego queda a disposición como recurso simbólico para interpretar un nuevo incremento de la inseguridad. Además, si bien la demanda punitiva era inicialmente menor en la CABA que en el GBA, reflejando en parte los distintos niveles de amenaza delictiva, una vez que la figura de Blumberg logró ocupar el espacio público y legitimar la demanda punitiva, los niveles de punitividad de la CABA se acercaron a los del GBA, por encima de su amenaza securitaria. Cabe igual advertir que ni aun en el apogeo de Blumberg existió un consenso punitivo sobre la inseguridad, aunque sí una preocupación en aumento.

En síntesis, al menos en el contexto metropolitano de Buenos Aires, a principios del siglo XXI, la demanda de mayores castigos hacia los delincuentes pareciera ser una reacción instrumental ante el incremento delictivo, pero de forma tardía y parcial. Asimismo, expresa la politización de la inseguridad en términos punitivos como resultado de las protestas de Blumberg, aunque no llega a generalizarse como tal. Mediante esta investigación se buscó aportar a una mayor comprensión de un fenómeno como la punitividad pública, que suele ser citada para legitimar medidas autoritarias en el sistema penal, pero que se desconoce su amplitud, su vinculación con el fenómeno delictivo y, más aún, su diferenciación de otro tipo de reacciones sociales hacia la inseguridad, tales como el temor al delito, la percepción de riesgos de victimización y la preocupación securitaria. 


\section{Referencias}

Annunziata, Rocío; Mauro, Sebastián; Slipak, Daniela (2006). Blumberg y el vínculo representativo. Liderazgos de opinión en la democracia de audiencia. En Ciudadanía, sociedad civily participación política (pp. 143-172), coordinado por Isidoro Cheresky. Buenos Aires: Miño y Dávila.

Applegate, Brandon; Cullen, Francis; Turner, Michael; Sundt, Jody (1996). Assessing Public Support for Three-strikes-and-you're-out laws: Global Versus Specific Attitudes. Crime \& Delinquency, 42, 517-534.

Banco de Desarrollo de América Latina (2014). Por una América Latina más segura: una nueva perspectiva para prevenir y controlar el delito. Bogotá: CAF.

Bateson, Regina (abril, 2009). The Political Consequences of Crime Victimization in Latin America. Trabajo presentado en Comparative Politics Workshop, Yale University, New Haven, Estados Unidos.

Beck, Ulrich (1998). La sociedad del riesgo. Hacia una nueva modernidad. Buenos Aires: Paidós.

Beck, Ulrich (2008). La sociedad del riesgo mundial. Barcelona: Paidós.

Becker, Gary (1968). Crime and Punishment: An Economic Approach. Journal of Political Economy, 4(76), 169-217.

Becker, Howard (1971). Los extraños. Buenos Aires: Tiempo Contemporáneo.

Ben-Yehuda, Nachman (2009). Foreword: Moral Panics-36 Years On. British Journal of Criminology, 49(1), 1-3.

Bergman, Marcelo; Kessler, Gabriel (2008). Vulnerabilidad al delito y sentimiento de inseguridad en Buenos Aires. Desarrollo Económico, 48(190-191), 209-234.

Bottoms, Anthony (1995). The Philosophy and Politics of Punishment and Sentencing. En The Politics of Sentencing Reform (pp. 17-49), editado por Chris Clarkson; Rod Morgan. Oxford: Oxford University Press.

Bourdieu, Pierre (200o). Cuestiones de sociología. Madrid: Istmo.

Brown, Elizabeth (2006). The Dog that did not Bark: Punitive Social Views and the "Professional Middle Classes”. Punishment \& Society, 8, 287-312.

Calzado, Mercedes (2011). Conmociones, amenazas y fisonomías victimizantes. Una reflexión sobre la reconfiguración de los límites de la política en las sociedades de seguridad. En Populismo punitivo y justicia expresiva (pp. 355-366), compilado por Mariano Gutiérrez. Buenos Aires: Fabián di Plácido. 
Calzado, Mercedes (2015). Inseguros: el rol de los mediosy la respuesta política frente a la violencia, de Blumberg a hoy. Buenos Aires: Aguilar.

Calzado, Mercedes (2018). Estado, usos y demandas. Gramáticas penales de las víctimas de inseguridad en la Argentina contemporánea. Athenea Digital, 18(2), e1303. https://doi. org/10.5565/rev/athenea.1303

Calzado, Mercedes; Van den Dooren, Sebastián (2009). ¿Leyes Blumberg? Reclamos de seguridad y reformas penales. Revista Delito y Sociedad, 1(27), 97-113.

Castel, Robert (2004). La inseguridad social. ¿Quées estar protegido? Buenos Aires: Manantial.

Champagne, Patrick (1990). Faire l'Opinion. París: Editions Minuit.

Chevigny, Paul (2003). The Populism of Fear: Politics of Crime in the Americas. Punishment or Society, 5, 77-96.

Cohen, Stanley (2002). Folk Devils and Moral Panics. The Creation of the Moods and Rockers ( $3 \cdot^{\mathrm{a}}$ ed.). Nueva York: Routledge.

Colombo, Rafael (2011). Populismo punitivo y politización de la (in)seguridad urbana en Argentina: programas electorales, políticas públicas y racionalidades de gobierno en tiempos electorales y más allá. En Populismo punitivo y justicia expresiva (pp. 183-218), compilado por Mariano Gutiérrez. Buenos Aires: Fabián di Plácido.

Costelloe, Michael; Chiricos, Ted; Gertz, Marc (2009). Punitive Attitudes toward Criminals: Exploring the Relevance of Crime Salience and Economic Insecurity. Punishment \& Society, 11, 25-49.

Cullen, Francis; Fisher, Bonnie; Applegate, Brandon (2000). Public Opinion about Punishment and Corrections. Crime and Justice, 27, 1-79.

Dammert, Lucía; Salazar, Felipe (2009). ¿Duros con el delito?: populismo e inseguridad en América Latina. Santiago de Chile: FLACSO.

Daroqui, Alcira (2009). Muertes silenciadas: la eliminación de los “delincuentes”. Buenos Aires: CCC.

Daroqui, Alcira; López, Ana Laura (2012). La cadena punitiva: actores, discursos y prácticas enlazadas. En Sujeto de castigos. Hacia una sociología de la penalidad juvenil (pp. 101-106), coordinado por Alcira Daroqui; Ana Laura López; Roberto Félix García. Buenos Aires: GESPDH.

Dirección Nacional de Política Criminal (DNPC) (2001-2005). Encuesta de victimización. Buenos Aires: Ministerio de Justicia y Derechos Humanos de la Nación.

Douglas, Mary (1992). Risk and Blame: Essays in Cultural Theory. Londres: Routledge.

Dubet, François (2002). Le déclin de l'institution. París: Seuil. 
Dubet, François (2016). ¿Por qué preferimos la desigualdad? Buenos Aires: Siglo XXI.

Durkheim, Emile (2004). La division social del trabajo. Buenos Aires: Libertador.

Elbert, Carlos Alberto (2007). Manual básico de criminología. Buenos Aires: EUDEBA.

Elias, Norbert (1993). El proceso de la civilización. Buenos Aires: FCE.

Fleitas, Diego; Otamendi, María Alejandra (2007). Homicidios, suicidios y uso de las armas de fuego en las provincias argentinas. En Las armas y las víctimas (pp. 65-88), compilado por Khatchik Der Ghougassian. Buenos Aires: UDESA.

Focás, Brenda (2017). Percepciones de la inseguridad y noticias policiales. Un recorrido de investigación. Revista Avatares de la Comunicación y la Cultura, 13, 1-9.

Galar, Santiago (2018). Apuntes para una problematización de la práctica pública de los familiares de víctimas de la inseguridad en la Argentina de la última década. DILEMAS, 11(1), 53-73. Recuperado de https://revistas.ufrj.br/index.php/dilemas/article/viewFile/17610/10792

Gamallo, Leandro (2017). Las formas de las represalias violentas en Argentina. Las acciones colectivas de violencia punitiva (2009-2015). Revista Delito y Sociedad, 44(26), 9-39.

Garland, David (2002). The Cultural Uses of Capital Punishment. Punishment $\&$ Society, 4, 459-488.

Garland, David (2005). La cultura del control. Barcelona: Gedisa.

Gerber, Mónica; Jackson, Jonathan (2012). Authority and Punishment: On the Ideological Basis of Punitive Attitudes towards Criminals. Londres: LSE.

Giddens, Anthony (1991). Modernity and Self-Identity. Stanford: Stanford University Press.

Green, David (2009). Feeding Wolves: Punitiveness and Culture. European Journal of Criminology, 6, 517-536.

Guemureman, Silvia (2011). La cartografía moral de las prácticas judiciales en los tribunales de menores. Los tribunales orales en la ciudad de Buenos Aires. Buenos Aires: Editores del Puerto.

Gutiérrez, Mariano (comp.), (2011). Populismo punitivoy justicia expresiva. Buenos Aires: Fabián Di Plácido.

Haddock, Geoffrey; Zanna, Mark (1998). Assessing the Impact of Affective and Cognitive Information in Predicting Attitudes toward Capital Punishment. Law and Human Behavior, $22,325-338$.

Hallsworth, Simon (2007). Repensando el giro punitivo. Economía del exceso y criminología del otro. Delito y Sociedad, 22, 57-74.

Hogan, Michael; Chiricos, Ted; Gertz, Marc (2005). Economic Insecurity, Blame, and Punitive Attitudes. Justice Quarterly, 22(3), 392-412. 
Hope, Tim; Sparks, Richard (2000). Crime, Risk and Insecurity. Londres: Routledge.

Hough, Mike; Roberts, Julian (1999). Sentencing Trends in Britain: Public Knowledge and Public Opinion. Punishment \& Society, 1, 11-26.

Hough, Mike; Roberts, Julian (2005). Understanding Public Attitudes to Criminal Justice. Maidenhead: Open University Press.

Instituto Nacional de Estadística y Censos (INDEC) (2001-2005). Encuesta permanente de hogares (EPH). Buenos Aires: INDEC.

Jacobs, David; Carmichael, Jason (2001). The Politics of Punishment Across Time and Space: A Pooled Time-Series Analysis of Imprisonment Rates. Social Forces, 8o, 91-121.

Jaitman, Laura (2017). The Costs of Crime and Violence: New Evidence and Insights in Latin America and the Caribbean. Washington, DC: Inter-American Development Bank.

Johnson, Devon (2009). Anger about Crime and Support for Punitive Criminal Justice Policies. Punishment \& Society, 11, 51-66.

Jones, Trevor; Newburn, Tim (2006). Three Strikes and You're Out: Exploring Symbol and Substance in American and British Crime Control Policies. British Journal of Criminology, 46, $781-802$.

Kessler, Gabriel (2008). Inseguridad subjetiva: nuevo campo de investigación y de políticas públicas. En Estado, democracia y seguridad ciudadana (pp. 107-142), compilado por Alejandro Álvarez; Julián Bertranou; Fernando Calderón; Damián Fernández Pedemonte; Sabina Frederic; Diego Galeano...; Marcelo Saín. Buenos Aires: PNUD.

Kessler, Gabriel (2009). El sentimiento de inseguridad. Buenos Aires: Siglo XXI.

Kessler, Gabriel (2011). La extensión del sentimiento de inseguridad en América Latina. Revista de Sociologia e Política, 19(40), 103-114.

King, Anna; Maruna, Shadd (2009). Is a Conservative Just a Liberal Who Has Been Mugged? Exploring the Origins of Punitive Views. Punishment \& Society, 11(2), 147-169.

Kühnrich, Bernd; Kania, Harald (2005). Attitudes towards Punishment in the European Union. Results from the 2005 European Crime Survey (ECSS) with Focus on Germany. Freiburg: Max Planck Institute for Foreign and International Criminal Law.

LaGrange, Hugues (2003). Demandes de securité. France, Europe, États-Unis. Paris: Seuil.

Latinobarómetro (2000-2009). Encuesta Latinobarómetro. Santiago de Chile: Fundación Latinobarómetro.

Lea, John; Young, Jock (2001). ¿Quéhacer con la leyy el orden? Buenos Aires: Editores del Puerto.

Lorenc-Valcarce, Federico (2011). La sécurité privée en Argentine : entre surveillance et marché. Paris: Karthala. 
Martini, Stella; Pereyra, Marcelo (2009). La irrupción del delito en la vida cotidiana. Buenos Aires: Biblos.

Masiva marcha frente al Congreso para pedir seguridad (1 de abril de 2004). Clarín. Recuperado de http://edant.clarin.com/diario/2004/o4/o1/um/m-734923.htm

Matthews, Roger (2005). The Myth of Punitiveness. Theoretical Criminology, 9, 175-201.

Míguez, Daniel; Isla, Alejandro (2010). Entre la seguridady el temor: instantáneas de la sociedad actual. Buenos Aires: Paidós.

Muchielli, Laurent (2008). La frénésie sécuritaire. Retour à l'ordre et nouveau contrôle social. Paris: La Découverte.

Murillo, Susana (2008). Colonizar el dolor. La interpelación ideológica del Banco Mundial en América Latina. El caso argentino desde Blumberg a Cromañón. Buenos Aires: CLACSO.

Otamendi, María Alejandra (2012). ¿Son las víctimas más punitivas? Un test a la paradoja de la victimización en los residentes del AMBA (2000-2010). Cuadernos de Estudios sobre Sistema Penal y Derechos Humanos, 2(2), 101-111. Recuperado de http://gespydhiigg.sociales.uba. ar/wp-content/uploads/sites/116/2013/o8/FINAL.pdf

Otamendi, María Alejandra (2013). Demandas de "mano dura": punitividad pública de los residentes del Área Metropolitana de Buenos Aires (200o-2010) [Tesis de doctorado en cotutela]. Facultad de Ciencias Sociales, Universidad de Buenos Aires y Centre d'Analyse et d'Intervention Sociologigues (CADIS), l'École des Hautes Études en Sciences Sociales (EHESS), Buenos Aires.

Otamendi, María Alejandra (2014). ¿Demandas de seguridad o demandas de "mano dura”? El "consenso punitivo" en cuestión en el AMBA (2000-2010). Revista Hologramática, 2(21), Recuperado de http://www.cienciared.com.ar/ra/usr/3/1568/holo21_vii_p155_174.pdf

Otamendi, María Alejandra (2015). Las actitudes punitivas de los residentes del AMBA (20012007) desde una perspectiva de clase: ¿dominación, resentimiento o vulnerabilidad? Revista Hologramática, 1(22), 63-92. Recuperado de http://www.cienciared.com.ar/ra/usr/3/1568/ holo22v1pp63_92_otamendi.pdf

Otamendi, María Alejandra (2016). Seguridad objetiva y subjetiva en América Latina: aclarando la paradoja. Revista Brasileira de Segurança Pública, 10(18), 56-87. Recuperado de http:// revista.forumseguranca.org.br/index.php/rbsp/article/view/593

Otamendi, María Alejandra; Zajac, Joaquín (2019). La re-militarización de la seguridad interior en Argentina: una amenaza para los derechos humanos y la vida de los jóvenes. Informe de Coyuntura, 8. Recuperado de http://webiigg.sociales.uba.ar/iigg/textos/documentos/ Ic8.pdf 
Palomino, Héctor (2004). Pobreza y desempleo en la Argentina. Problemática de una nueva configuración social. Buenos Aires: CESPA-FCE/UBA.

Pegoraro, Juan (2011). La política penal de la defensa social. En Populismo punitivo y justicia expresiva (pp. 21-41), compilado por Mariano Gutiérrez. Buenos Aires: Fabián di Plácido.

Pita, María Victoria (2011). Violencia policial y demandas de justicia: algunas formas de la protesta popular. En Populismo punitivo y justicia expresiva (pp. 221-263), compilado por Mariano Gutiérrez. Buenos Aires: Fabián di Plácido.

Pratt, John (2005). Elias, Punishment, and Decivilization. En The New Punitiveness. Trends, theories, perspectives (pp. 256-271), editado por John Pratt; David Brown; Mark Brown; Simon Hallsworth; Wayne Morrison. Cullompton: Willan Publishing.

Pratt, John; Brown, David; Brown, Mark; Hallsworth, Simon; Morrison, Wayne (2005). The New Punitiveness: Trends, Theories, Perspectives. Cullompton: Willan Publishing.

Rangugni, Victoria (2011). Delito, (in)seguridad y redefinición de las relaciones de gobierno en la Argentina neoliberal. En Populismo punitivo y justicia expresiva (pp.367-386), compilado por Mariano Gutiérrez. Buenos Aires: Fabián di Plácido.

Rapoport, Mario (2005). Historia económica, políticay social de la Argentina. Buenos Aires: Ariel.

Robert, Philippe; Pottier, Marie-Lys (2004). Les préoccupations sécuritaires : une mutation? Revue française de Sociologie, 45, 211-241.

Roberts, Julian; Hough, Mike (2005). Understanding Public Attitudes to Criminal Justice. Berkshire: Open University Press.

Roberts, Julian; Stalans, Loretta; Indermaur, David; Hough, Mike (2003). Penal Populism and Public Opinion: Lessons from Five Countries. New York: Oxford University Press.

Roché, Sébastian (1993). Le sentiment d'insécurité. Paris: PUF.

Roché, Sébastian (1998). Expliquer le sentiment d'insécurité: pression, exposition, vulnérabilité et acceptabilité. Revue française de science politique, 48(2), 274.

Rodríguez-Alzueta, Esteban (2014). Temory control. La gestión de la inseguridad como forma de gobierno. Buenos Aires: Futuro Anterior.

Ronconi, Lucas (2009). Los costos de la delincuencia en Argentina: estimación en base a encuestas de victim ización. Buenos Aires: UTDT/LICIP.

Rosanvallon, Pierre (2007). La contrademocracia: la política en la era de la desconfianza. Buenos Aires: Manantial.

Rosenberg, Morris; Turner, Ralph (1992). Social Psychology. Sociological perspectives. Londres: Transaction Publishers. 
Rossi, Peter; Berk, Richard (1997). Just Punishments: Federal Guidelines and Public Views Compared. New York: Aldine de Gruyter.

Rountrée, Pamela (1998). A Reexamination of the Crime-Fear Linkage. Journal of Research in Crime and Delinquency, 35, 341-372.

Ryan, Mick (2005). Engaging with Punitive Attitudes towards Crime and Punishment. Some Strategic Lessons from England and Wales. En The New Punitiveness. Trends, Theories, Perspectives (pp.139-149), editado por John Pratt; David Brown; Mark Brown; Simon Hallsworth; Wayne Morrison. Cullompton: Willan Publishing.

Sales, Stephen (1973). Threat as a Factor in Authoritarianism: An Analysis of Archival Data. Journal of Personality and Social Psychology, 28, 44-57.

Sartori, Giovanni (1998). Homo videns. La sociedad teledirigida. Madrid: Taurus.

Savelsberg, Joachim (1999). Knowledge, Domination, and Criminal Punishment. American Journal of Sociology, 99(4), 911-943.

Schillagi, Carolina (2009). “Inseguridad”, reclamos al Estado y actuación pública de organizaciones y familiares de víctimas de delitos en la Argentina (2004-2006). En Movilizaciones sociales ¿nuevas ciudadanías? Reclamos, derechos, Estado en Argentina, Bolivia, Brasil (pp. 109-159), coordinado por Gabriela Delamata. Buenos Aires: Biblos.

Schuman, Howard; Presser, Stanley (1996). Questions and Answers in Attitude Surveys: Experiments on Question Form, Wording, and Context. Thousand Oaks: Sage.

Segato, Rita (2003). Las estructuras elementales de la violencia. Bernal: Prometeo-Unqui.

Simon, Jonathan (2007). Governing through Crime: How the War on Crime Transformed American Democracy and Created a Culture of Fear. Oxford: Oxford University Press.

Sistema Estadístico de Salud (SES) (2001-2005). Base de datos de defunciones. Buenos Aires: Ministerio de Salud.

Sistema Nacional de Información Criminal (SNIC) (2002, 2003, 2008). Informe anual. Buenos Aires: Ministerio de Justicia y Derechos Humanos de la Nación.

Smulovitz, Catalina (2003). Citizen Insecurity and Fear: Public and Private Responses in Argentina. En Crime and Violence in Latin America (pp. 125-152). Washington, DC: WWCS.

Sozzo, Máximo (200o). Pintando a través de números. Fuentes estadísticas de conocimiento y gobierno democrático de la cuestión criminal en la Argentina. Recuperado de http://www. ilsed.org/index.php?option=com_docman\&task=doc_view\&gid=159\&itemid $=44$

Sozzo, Máximo (2003). ¿Contando el delito? Análisis crítico y comparativo de las encuestas de victimización en Argentina. Revista Cartapacio de Derecho, 5, 1-143. 
Sozzo, Máximo (2007). ¿Metamorfosis de la prisión? Proyecto normalizador, populismo punitivo y "prisión-depósito". URVIO, 1, 88-116.

Sozzo, Máximo (2016). Postneoliberalismo y penalidad en el Cono Sur. Buenos Aires: CLACSO.

Sprott, Jane; Doob, Anthony (1997). Fear, Victimization, and Attitudes to Sentencing, the Courts, and the Police. Canadian Journal of Criminology, 39, 275-291.

Stevens, Daniel; Bishin, Benjamin; Barr, Robert (2006). Authoritarian Attitudes, Democracy, and Policy Preferences among Latin American Elites. American Journal of Political Science, 50, 606-620.

Tedesco, Laura (2000). La ñata contra el vidrio: Urban Violence and Democratic Governability in Argentina. Bulletin of Latin American Research, 19, 527-545.

Tonkonoff, Sergio (2011). Mito-lógicas. La cuestión criminal en el centro de la cultura. En Populismo punitivo y justicia expresiva (pp.43-56), compilado por Mariano Gutiérrez. Buenos Aires: Fabián di Plácido.

Tulchin, Joseph; Fagan, Graig (2003). Perfil actual de la seguridad ciudadana e impacto en la gobernabilidad democrática. Aportes desde Latinoamérica. En Entre el crimen y el castigo: seguridad ciudadana y control democrático en América Latina y el Caribe (pp.13-29). Caracas: Nueva Sociedad.

Tyler, Tom; Boeckmann, Robert (1997). Three Strikes and You Are Out, but Why? The Psychology of Public Support for Punishing Rule Breakers. Law \& Society Review, 31, 237-266.

Tyler, Tom; Weber, Reneé (1982). Support for the Death Penalty: Instrumental Response to Crime or Symbolic Attitude? Law \& Society Review, 17, 21-46.

Van den Dooren, Nicolás (2011). La Creación de la Ley Penal. El contexto socio-político del período legislativo 2004. En Populismo punitivo y justicia expresiva (pp. 121-149), compilado por Mariano Gutiérrez. Buenos Aires: Fabián di Plácido.

Van Evera, Stephen (2002). Guía para estudiantes de ciencia política. Barcelona: Gedisa.

Vilker, Shila (2006). Truculencia. Buenos Aires: Prometeo.

Wacquant, Loic (2005). The Great Penal Leap Backward: Incarceration in America from Nixon to Clinton. En The New Punitiveness. Trends, theories, perspectives (pp. 3-26), editado por John Pratt; David Brown; Mark Brown; Simon Hallsworth; Wayne Morrison. Cullompton: Willan Publishing.

Young, Jock (2007). The Vertigo of Late Modernity. Londres: Sage.

Zimring, Franklin; Johnson, David (2006). Public Opinion and the Governance of Punishment in Democratic Political Systems. Annals of the American Academy of Political and Social Science, 605, 266-280. 


\section{Anexo}

CUADRO 3 Características de las muestras de la EV de la DNPC en el AMBA

\begin{tabular}{|c|c|c|c|}
$\begin{array}{c}\text { Año } \\
\text { de referencia }\end{array}$ & $\begin{array}{c}\text { Fecha del trabajo } \\
\text { de campo }\end{array}$ & $\begin{array}{c}\text { Tamaño } \\
\text { de la muestra }\end{array}$ & $\begin{array}{c}\text { Margen de } \\
\text { error general }\end{array}$ \\
\hline 2001 & Febrero a marzo de 2002 & 8932 casos & $\pm 1,60 \%$ \\
\hline 2002 & $\begin{array}{c}\text { Diciembre de } 2002, \\
\text { y marzo a abril de } 2003\end{array}$ & 6405 casos & $\pm 1,80 \%$ \\
\hline 2003 & Marzo a abril de 2004 & 5260 casos & $\pm 1,95 \%$ \\
\hline 2005 & Marzo a mayo de 2006 & 4761 casos & $\pm 2,04 \%$
\end{tabular}

Fuente: elaboración propia a partir de la DNPC (2001-2005); INDEC (2001-2005).
\begin{tabular}{l|l} 
CUADRO 4 & Pregunta seleccionada del cuestionario de la EV de la DNPC para
\end{tabular} medir orientación general de la punitividad pública en el AMBA, según tipo de prevención

\section{Pregunta: ¿Qué medidas piensa que deberían tomarse para mejorar el tema de la seguridad? (primera mención)}

\section{Respuestas}

\section{Tipo de prevención}

Que hayan penas más severas/nuevas leyes más severas Prevención especial y general negativa

Pena de muerte

Mejorar funcionamiento del Poder Judicial/ sentencias a delincuentes

Prevención especial y general positiva

Que se cumplan las leyes

Más vigilancia/más presencia policial

Terminar con la corrupción policial/policía

Prevención situacional con intervención policial más decente

Más y mejor educación/más presupuesto para educación

Prevención social

Bajar la desocupación 
\begin{tabular}{l|l} 
CUADRO 5 & Pregunta seleccionada del cuestionario de la EV de la DNPC para
\end{tabular} medir orientación específica de la punitividad pública en el AMBA

Pregunta: las personas tienen distintas opiniones acerca de qué penas deberían imponerse a los delincuentes. Tomemos por ejemplo el caso de un hombre de $\mathbf{2 0}$ años a quien se lo encuentra culpable de robo en vivienda por segunda vez. Esta vez, robó un televisor a color. ¿Cuál de las siguientes penas considera usted que es la más apropiada para un caso así?

\section{Opciones de respuesta (respuesta única):}
1. Multa
2. Prisión
3. Servicio comunitario
4. Libertad condicional
5. Otra pena

\section{CUADRO 6 $\mid$ Mediciones de victimización}

Para medir los niveles de victimización, más que el criterio legal se siguió el sociológico, empleado en otros estudios donde se demostró que resulta significativo diferenciar entre la victimización que ocurrió en una interacción cara a cara, como los ataques físicos o sexuales, las amenazas de violencia y los robos con violencia; de la victimización sin contacto, como los hurtos en vivienda o vandalismos de propiedad personal (Bergman; Kessler, 2008; Rountrée, 1998). Por lo tanto, a partir de las preguntas en la EV de la DNPC se obtuvieron los siguientes indicadores:

\section{Tipo de victimización}

\section{Medición}

Porcentaje de encuestados que contestaron afirmativamente que un miembro de su hogar fue víctima, en el último año, de al

General menos uno de los siguientes delitos: hurto en vivienda, de vehículo, de objeto de vehículo; hurto personal, de moto, ciclomotor o bicicleta; vandalismo sobre vehículo; robo con violencia; lesiones o amenazas; ofensa sexual; secuestros; homicidios.

Porcentaje de encuestados que contestaron afirmativamente que

Contra la propiedad (sin contacto)

Violenta (con contacto) un miembro de su hogar fue víctima en el último año de al menos uno de los siguientes delitos: hurtos en vivienda, de vehículo, de objeto de vehículo, hurtos personales, hurto de moto, ciclomotor o bicicleta, vandalismo sobre vehículo.

Porcentaje de encuestados que contestaron afirmativamente que un miembro de su hogar fue víctima en el último año de al menos uno de los siguientes delitos: robo con violencia, lesiones o amenazas, ofensa sexual, secuestros, homicidios. 